\section{OPEN ACCESS}

Edited by:

Elizabeth Secord,

Wayne State University, United States

Reviewed by:

Sophia Tsabouri,

University of loannina, Greece

*Correspondence:

Francesca Saretta francescasaretta@gmail.com

Specialty section:

This article was submitted to

Pediatric Immunology,

a section of the journal

Frontiers in Pediatrics

Received: 25 October 2021 Accepted: 17 November 2021 Published: 23 December 2021

Citation:

Saretta F, Giovannini M, Mori F, Arasi S, Liotti L, Pecoraro L, Barni S, Castagnoli R, Mastrorilli C, Caminiti L,

Marseglia GL and Novembre E (2021) Alpha-Gal Syndrome in Children: Peculiarities of a "Tick-Borne" Allergic

Disease. Front. Pediatr. 9:801753. doi: 10.3389/fped.2021.801753

\title{
Alpha-Gal Syndrome in Children: Peculiarities of a "Tick-Borne" Allergic Disease
}

\begin{abstract}
Francesca Saretta ${ }^{1 *}$, Mattia Giovannini ${ }^{2}$, Francesca Mori ${ }^{2}$, Stefania Arasi ${ }^{3}$, Lucia Liotti ${ }^{4}$, Luca Pecoraro 5,6 , Simona Barni ${ }^{2}$, Riccardo Castagnoli ${ }^{7}$, Carla Mastrorilli ${ }^{8}$, Lucia Caminiti $^{9}$, Gian Luigi Marseglia ${ }^{7}$ and Elio Novembre ${ }^{2}$

'Pediatric Department, Latisana-Palmanova Hospital, Azienda Sanitaria Universitaria Friuli Centrale, Udine, Italy, ${ }^{2}$ Allergy Unit, Department of Pediatrics, Meyer Children's University Hospital, Florence, Italy, ${ }^{3}$ Translational Research in Pediatric Specialties Area, Division of Allergy, Bambino Gesù Children's Hospital (IRCCS), Rome, Italy, ${ }^{4}$ Department of Pediatrics, Salesi Children's Hospital, AOU Ospedali Riuniti Ancona, Ancona, Italy, ${ }^{5}$ Department of Medicine, University of Verona, Verona, Italy, ${ }^{6}$ Maternal and Child Department, ASST Mantua, Mantova, Italy, ${ }^{7}$ Department of Pediatrics, Pediatric Clinic, Fondazione IRCCS Policlinico San Matteo, University of Pavia, Pavia, Italy, ${ }^{8}$ Pediatric Unit and Emergency, University Hospital Consortium Corporation Polyclinic of Bari, Pediatric Hospital Giovanni XXIII, Bari, Italy, ${ }^{9}$ Department of Human Pathology in Adult and Development Age "Gaetano Barresi," Allergy Unit, Department of Pediatrics, AOU Policlinico Gaetano Martino, Messina, Italy
\end{abstract}

The alpha-gal syndrome is an allergic syndrome that comprises two clinical pictures: an immediate hypersensitivity to drugs containing alpha-gal and a delayed hypersensitivity to the ingestion of red mammalian meat. This allergic syndrome is often under-recognized, and patients are mislabeled with diagnosis as spontaneous urticaria or idiopathic anaphylaxis. Even though less frequently, children could also be of interest, especially in tick-endemic areas. In most cases, a positive anamnesis for tick bites months before the onset of symptoms is recorded. The clinical manifestations could range from asymptomatic cases to severe anaphylaxis. The most frequently used diagnostic test is the determination of specific lgE for alpha-gal. Oral provocation test is usually reserved to unclear cases or to verify tolerance after diet. No long-term follow-up studies have been published, although an elimination diet could lead to a decrease of specific IgE for alpha-gal and a possible reintroduction of some avoided foods. This paper provides a literature review, focused on pediatric age, and an evaluation of available diagnostic tests. We analyze the correlation between tick bites and symptom onset and unfold the different clinical pictures to help clinicians to promptly recognized this syndrome. Lastly, we address unmet needs in this specific allergy.

Keywords: food allergy, alpha-gal ( $\alpha$-gal), delayed anaphylaxis, red meat allergy, children, cetuximab

\section{INTRODUCTION}

The alpha-gal syndrome (AGS) is an allergic syndrome comprising two scenarios: an immediate hypersensitivity to drugs containing alpha-gal and a delayed hypersensitivity due to the ingestion of red meat (intended as meat from non-primate mammals). The allergic response observed is due to the production of specific IgE (sIgE) for the disaccharide galactose- $\alpha$-1,3-galactose (alphagal or $\alpha$-gal), which is expressed on the surface of glycolipids and glycoprotein of mammalian cells and synthesized by the galactosyl- $\alpha-1,3$-galactosyl-synthetase. In primates, the alpha-gal is 
not expressed due to a genetic loss-of-function mutation of the GGTA1 gene and is recognized as non-self. Since the 80 's, IgG-IgA-IgM for alpha-gal have been described, as a protection against parasitosis and the main cause of xeno-transplant reject reactions (1). It is still not clear what drives the IgE production for alpha-gal (sIgE- $\alpha$-gal), but in most cases, there is a positive anamnesis for tick bites in the months before the onset of symptoms. It has also been observed that there is a higher incidence of cases in distribution areas of some species of ticks: in the United States of America, "lone star" Amblyomma americanum; in Australia, Ixodes holocyclus; in Europe, Ixodes ricinus; and in Asia, Ixodes nipponensis.

\section{BIOLOGICAL SOURCES OF ALPHA-GAL}

Alpha-gal is expressed in all non-primate mammals (not only in beef, pork, elk, reindeer, and lamb but also in small mammals such as squirrels or beaver), and it could be found in meats, internal organs, meat by-products, gelatin, milk, and dairy products. Alpha-gal is resistant to heat and pepsinic lysis (2) and is therefore present also in all industrial by-products such as food and drugs and even in snake poison antidotes (3).

Alpha-gal is also found in carrageenan, obtained from boiled red algae (Chondrus crispus and Gigartina mamitiosa), frequently used in food and drug preparations and identified as E407 preservatives. Carrageenan could be found, e.g., as a clarifying agent, as a hydrating agent for foods, in powdered infant's milk, and in toothpaste.

It has been demonstrated that alpha-gal could also be present in porcine and bovine substitute's heart valves; an allergic sensitization to alpha-gal has been associated to an early valvular deterioration (4) and to peri-operative anaphylaxis after valvular substitution (5). In particular, in subjects younger than 65 years old and sensitized to alpha-gal, an increase of atherosclerosis and plaque instability have been observed (6).

In a recent study (7), an increase of sIgE- $\alpha$-gal after multiple Hymenoptera stings has been observed with further decrease after 6-8 weeks. This could be due to the increase of Api m5, a dipeptidyl-peptidase similar to an enzyme found in tick saliva. Researchers are still investigating if other parasites, such as Trombicula, could be a carrier of alpha-gal (8).

\section{FROM THE FIRST CASE REPORTS TO SENSITIZATION AND CLINICAL MANIFESTATIONS}

A detailed chronology of scientific discoveries about AGS starts in 1989, when Mrs. Sandra Latimer and Dr. Antony Deutsch (9) reported in Georgia (USA) the first case reports of delayed red meat allergy with a possible correlation to tick bites. In 2007, Van Nunen et al. (10) reported an Australian case series of delayed red meat allergy, with patients recalling I. holocyclus tick bites before symptom onset and having positive prick test or specific IgE to red meat. In the same year, O'Neil et al. (11) observed a higher frequency of cetuximab hypersensitivity reactions (HRs) in south-east of USA, arguing firstly a possible role of specific
IgE toward cetuximab, and Qian et al. (12) demonstrated alphagal in F portion of cetuximab. In 2008, Chung et al. (13) found positive sIgE cetuximab in cetuximab-allergic patients before drug infusion, and in 2009, Commins et al. $(14,15)$ published a case series of delayed red meat allergy in areas with overlapping cetuximab HR reports and demonstrated the correlation of these reactions to previous tick bites and further increase of $\operatorname{sigE}-\alpha$ gal (interestingly at first in researchers and then in patients). A. americanum was found responsible for those sensitization. Finally, in 2013, Hamsten et al. (16) demonstrated the presence of alpha-gal in tick saliva and the correlation between tick bites and following sensitization to alpha-gal.

Some mechanisms have been proposed to explain how alphagal enters in tick intestine: the tick itself produces the alphagal, the alpha-gal comes from a previous tick meal on a carrier animal, and the alpha-gal is expressed by some symbionts in tick saliva (17). Another unclear question is how the tick bite induces sIgE- $\alpha$-gal production. Some hypotheses have been suggested:

1) The alpha-gal in tick saliva, once inoculated, interacts with antigen-presenting cells (APC) and B cells, directly stimulating sIgE- $\alpha$-gal production.

2) Tick bite inoculates the alpha-gal and some adjuvants, which drive the isotypic B cell switch from IgG/IgM- $\alpha$-gal to sIgE- $\alpha$ gal (18).

3) Tick bite induces a skin barrier trauma or interferes with skin microbioma, causing the production of pro-allergic molecules, which drive the isotypic B cell switch (19).

However, skin trauma plays a pivotal role in altering the micro-environment, favoring the switch toward IgE and Th2 immunity by promoting the release of TSLP, IL25, and IL33 $(20,21)$. Basophils could also play a role, as some studies have demonstrated (22-24).

\section{THE DELAYED TIMING IN ALPHA-GAL FOOD ALLERGY}

Once ingested through a meal with red meat products or byproducts, glycolipids and glycoproteins expressing alpha-gal are absorbed in the gastrointestinal tract, through chylomicrons entering the lymphatic system (thoracic duct) and systemic circulation (superior vena cava). In the following $2-4 \mathrm{~h}$, chylomicrons reduce their diameter from 400 to $20 \mathrm{nM}$ in low-density lipoproteins. With this diameter, they could cross skin interstitial tissues or vessel walls and activate mast cells and basophils. Once cross-linked with IgE-FceRI complex on basophils and mast cells, which express the same high-affinity IgE receptor, degranulation starts with subsequent IgE-mediated reaction. The whole interval time needed for these processes could therefore explain the delay of symptoms in AGS by food ingestion $(25,26)$ (Figure 1).

\section{CLINICAL MANIFESTATIONS OF AGS}

Sensitization usually occurs through inoculation of alpha-gal via tick bites, which could lead to the following: 


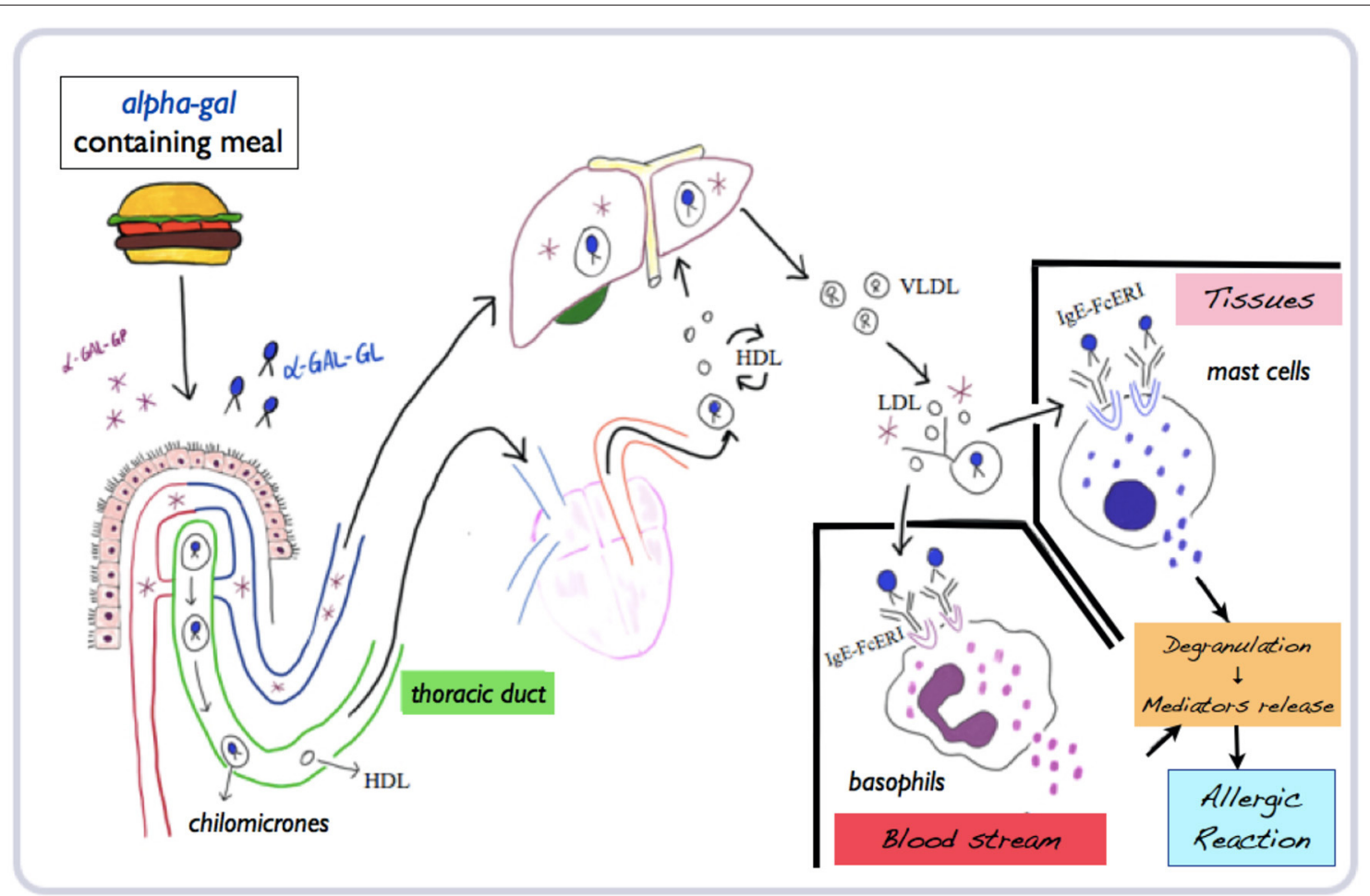

FIGURE 1 | Mechanisms of absorption, processing, and metabolization of alpha-gal and subsequent allergic reaction. Adapted and modified from Wilson and Platts-Mills (26) (mod.) ( $\alpha$-gal-GP, glycoproteins; $\alpha$-gal-GL, glycolipids; HDL, high-density lipoproteins; LDL, low-density lipoproteins; VLDL, very-low density lipoproteins).

\section{Asymptomatic Sensitization}

A low-grade sensitization to alpha-gal is not always correlated with clinical manifestations. In a study on German adults (27) with occupational risk for tick bites (hunters and rangers), $35 \%$ of patients had $\operatorname{sigE}-\alpha$-gal $>0.10 \mathrm{kUI} / \mathrm{l}$ and $19.3 \% \mathrm{had}$ sIgE- $\alpha$-gal $>0.35 \mathrm{kUI} / \mathrm{l}$. Only five patients, though, referred allergic symptoms after red meat ingestion, all with $\operatorname{sigE}-\alpha-$ gal $>0.35 \mathrm{kUI} / \mathrm{l}(8.6 \%$ total). Importantly, no differences, in terms of demographics and clinical data, were found, within the sIgE- $\alpha$-gal $>0.35 \mathrm{kUI} / \mathrm{l}$ patient group, between patients who reported meat allergy or not. Interestingly, four out of five of these patients were diagnosed with AGS while participating in the study (27).

\section{An Allergic Reaction After Ingestion of Food Containing Alpha-Gal}

This allergy has unusual characteristics: (a) symptoms are delayed (often after $3-6 \mathrm{~h}$ as a timing of onset) but clinically immediate; (b) it does not appear after every ingestion; and (c) it could start years after sensitization and for food previously tolerated (28). A wide intra-individual variability of the trigger dose has been observed (probably due to allergic co-factors and different alpha-gal quantities in food). Patients with mastocytosis seem to react to lower doses (17).

\section{Allergic Reaction to Drugs and Vaccines Containing Alpha-Gal}

Parenteral administration is the main sensitization form, with immediate reactions. In AGS, the most frequent culprit drug is cetuximab, a monoclonal antibody prescribed for colorectal cancer. Vaccines containing gelatin could be responsible for allergic reactions, since gelatin present in vaccines is usually pork derived (29). Therefore, patients must be instructed to check vaccine composition in order to avoid allergic reactions.

\section{Allergic Reactions After Further Tick Bites}

Repeated tick bites could lead to local and systemic reactions such as anaphylaxis. Tick bite anaphylaxis, typically severe, has been reported mainly in an endemic area in Australia, and it is more frequent in adults and if the tick is removed or tingled, and it is preventable if the tick is killed in situ (30).

\section{CLINICAL AND ALLERGOLOGICAL CHARACTERISTICS OF AGS PEDIATRIC PATIENTS}

\section{Mixed Adult/Children Studies}

The study by Mabelane et al. (31) included 131 subjects from a South African rural area (age 4-65 years old; 65\%> 13 years old), all referring to delayed red meat reactions. In 114 patients, an oral provocation test has been performed (positive in $71.1 \%$ ), 
and no reactions were recorded in control subjects with positive sIgE- $\alpha$-gal. In the patient group, two different phenotypes have been observed: $21 \%$, mostly women, complained only abdominal cramps; $79 \%$ showed different combinations of abdominal symptoms (77.7\%), skin and mucous membranes reactions (53.1\%), and respiratory or hypo-perfusion symptoms (4.9\%). No significant differences were observed in regard to age, symptom onset, alpha-gal sensitization, and sIgE- $\alpha$-gal/total sIgE ratio.

Wilson et al. (32) have recently confirmed these data in another mixed adult/children population. In 35 children (5-18 years old) with delayed red meat reactions $(89 \%,>2 \mathrm{~h}$ after ingestion), $97 \%$ showed sIgE- $\alpha$-gal $>0.35 \mathrm{kUI} / \mathrm{l}$, and $100 \%$ recalled a tick bite in the previous 10 years. Among the children, $89 \%$ had urticaria, $49 \%$ had anaphylaxis, $66 \%$ had gastrointestinal symptoms, and $51 \%$ required ER evaluation. In this population, higher levels of sIgE- $\alpha$-gal were observed in urticaria/anaphylaxis compared to isolated gastrointestinal symptoms $(p=0.002)$. It may therefore be possible that isolated abdominal pain is an under-reported and under-diagnosed feature of AGS, as also reported by other authors (33).

\section{Pediatric Studies}

In 2013, the first pediatric study has been published by Kennedy et al. (34). Fifty-one children (4-17 years old) with delayed red meat allergic reactions (92\% urticaria, 31\% angioedema, $64 \%$ gastrointestinal symptoms, and $44 \%$ anaphylaxis) have been analyzed. Most of them (88\%) showed positive sIgE- $\alpha$-gal, half required ER evaluation, and 19\% required adrenaline treatment. All parents recalled a tick bite before symptom onset, and $87 \%$ remembered the tick bite as persistently itching and hyperemic.

Donaldson and Le (35) reported a 3.3\% prevalence of AGS in a 5-year period (2014-2018) in children from Missouri with food allergy diagnosis. Children presented urticaria in $78 \%$, anaphylaxis in $29 \%$, angioedema in $21 \%$, and gastrointestinal symptoms in $17 \%$ of cases, and ER evaluation was required in $32 \%$ of cases.

Clinical and allergological characteristics of the pediatric case series are briefly reported in Table 1. Other case reports of AGS in childhood have been published (36-40).

\section{Adult/Children Differences}

AGS shows different characteristics in children compared to adults. Children seem to have a lower incidence of AGS [13\% in the study by Wilson et al. (32) and $35 \%$ in the study by Mabelane et al. (31)], lower sIgE- $\alpha$-gal levels (although there is no difference in reaction timing or nature or exposure to tick bites), a restricted number of trigger foods, a predominance of gastrointestinal symptoms, and exercise as the main allergic co-factor (7).

\section{Risk Factors}

Some risk factors have been associated with a higher risk of developing AGS $(7,41)$ :

- Outdoor works and hobbies (forest guards, hunters, and hikers) and environmental conditions that increase the development and spread of ticks;

- Non-B blood types;
- Allergic co-factors (e.g., drugs, alcohol, and exercise);

- Age: possibly correlated to the studied population, though, e.g., in the study of Mabelane et al. (31) patients have a younger age probably due to an earlier environmental exposure;

- Atopy: the association has not been clarified yet (42);

- Cat allergy: alpha-gal epitope is also present on cat, implying a possible association between AGS and cat dander sensitization. However, not all studies agree on this hypothesis (43);

- Meat type (giblets vs. lean cut): Morisset et al. (44) demonstrated a correlation between meat type and inhibitory properties of alpha-gal, showing that the kidney has a higher alpha-gal content;

- Type of exposure: parenteral exposure is correlated with more severe reactions compared to ingestion.

\section{Protective Factors}

$\mathrm{B} / \mathrm{AB}$ blood types seem to act as a protective factor (41). This is explained looking at the similarity between alpha-gal and $B$ antigen in $\mathrm{ABO}$ system: the only difference is a fucose residue on $B$ antigen. Many studies have underlined that $B$ or $A B$ blood type subjects are under-represented in AGS case series, with lower levels of sIgE- $\alpha$-gal production (45-47).

\section{DIAGNOSIS}

As in adults, the diagnosis is based on clinical history and allergy tests.

\section{Clinical History}

1) Clear up when signs and symptoms appear: delayed reactions begin at least $2 \mathrm{~h}$ after meat ingestion, while parenteral administration evokes immediate reactions;

2) Ask for previous tick bites and bite reactions (as persistent itchiness or redness);

3) Evaluate the number and characteristics of episodes;

4) Check for possible allergic co-factors;

5) Think about AGS in any allergic reaction without apparent cause. In a study on teenagers and adults (48), initially classified as idiopathic anaphylaxis, AGS was the definitive cause in $33 \%$;

6) As suggested by Kennedy et al. (34), in children, especially those older than 5 years old, with delayed reaction to red meat or dairy products previously tolerated, AGS must be excluded.

\section{Allergy Tests}

No pediatric studies have specifically evaluated sensitivity and specificity of allergy tests, and most of them rely on the same positivity cut-off for skin tests and sIgE- $\alpha$-gal.

Commercial prick tests for red meat showed a low sensibility and are not recommended (14). Cooked red meat, gelatin, and cetuximab prick-by-prick seem to be more useful $(14,49)$. In case of isolated beef meat prick positivity, milk proteins must be checked to exclude a milk allergy (50). In a study by Kennedy et al. (34), milk protein positivity in children with no history of milk allergy and who currently eat milk and dairy products without reactions has been reported. Intradermal tests with red 
TABLE 1 | Clinical and allergological characteristics of an AGS pediatric case series.

\begin{tabular}{|c|c|c|c|c|c|c|c|c|c|c|}
\hline \multirow[t]{2}{*}{ Author } & \multirow[t]{2}{*}{$n$} & \multirow{2}{*}{$\begin{array}{l}\text { Age } \\
\text { Years }\end{array}$} & \multirow{2}{*}{$\begin{array}{c}\text { Total lgE } \\
\text { kUl/I }\end{array}$} & \multirow{2}{*}{$\begin{array}{c}\text { slgE } \alpha-g a l \\
\text { kUI/I }\end{array}$} & \multicolumn{4}{|c|}{ Clinical manifestations (\%) } & \multirow[t]{2}{*}{ ER\% } & \multirow[t]{2}{*}{ Ref } \\
\hline & & & & & Urticaria & Angioedema & GI & Anaphylaxis & & \\
\hline Wilson et al. & 35 & 13 & 170 & 8.2 & 93 & - & 66 & 49 & 51 & $(32)$ \\
\hline Kennedy et al. & 51 & 12 & 147 & 8 & 92 & 31 & 64 & 44 & 50 & (34) \\
\hline Donaldson and Le & 42 & 9.95 & - & 2.9 & 78 & 21.9 & 17 & 29.2 & 32 & (35) \\
\hline
\end{tabular}

Ref, references, GI, gastrointestinal, ER, emergency room access.

meat extracts are not recommended for an elevated anaphylaxis risk. Some studies suggest more reliable results with gelatin intradermal test $(49,51-53)$.

Most allergological clinics rely on specific IgE for alpha-gal. Commercially available kits are Phadia-Thermo Fisher in Europe and Viracor-Eurofins in the United States. It is recommended to evaluate both sIgE- $\alpha$-gal and total $\operatorname{IgE}$ and calculate the ratio. Scientific experts suggest to consider as positive an sIgE- $\alpha$-gal level $>0.1 \mathrm{kUI} / \mathrm{l}$ (92.3\% specificity, 100\% sensibility in patients with clinical AGS) (7). However, the most accurate diagnosis is performed with sIgE- $\alpha$-gal $>2 \mathrm{kUI} / \mathrm{l}$ and $\operatorname{sIgE}-\alpha$-gal/IgE total ratio $>2 \%$ (54). Correlations have been demonstrated neither between sIgE- $\alpha$-gal and severity of reactions (7) nor between sIgE- $\alpha$-gal and reaction timing (32). Commins (7) recommends to test sIgE for milk proteins, cat dander, red meat (beef or pork), and beef/pork gelatin, especially in patients with positive sIgE- $\alpha-$ gal and negative clinical history or in patients clinically suspected with negative sIgE- $\alpha$-gal (54). In this case, sIgE- $\alpha$-gal for cat serum albumin (Fel d 2) must be checked to identify cat-pork syndrome (7).

Recently, the basophil activation test has shown a possible usefulness in distinguishing symptomatic patients with AGS from those with laboratory-isolated sensitization (55).

Oral provocation test could be useful to confirm AGS diagnosis in doubtful cases or asymptomatic sensitization, but it is not standardized yet, especially in regard to the quantity and quality of meat to be tested. Morisset et al. (44) designed a 3day protocol with increasing doses of pork kidney, reaching a cumulative dose of $965 \mathrm{mg}$ at day $1,7 \mathrm{~g}$ at day 2, and $150 \mathrm{~g}$ at day 3. Mabelane et al. (31) performed an oral provocation test with beef sausages (one sausage of $63 \mathrm{~g}$ for body weight $<30 \mathrm{~kg}$, two sausages for weight $30-60 \mathrm{~kg}$, and three sausages for weight $>60 \mathrm{~kg})$.

\section{MANAGEMENT}

Once the AGS diagnosis is clear, it is important to discuss with the patient about diet adjustment, further tick bite avoidance, and treatment plan.

Elimination diet could be set upon clinical history and comprises the elimination of all mammalian meats. The patient should be taught on label reading and instructed to avoid meat and by-products, especially internal organs (spleen and liver), which could be used as an ingredient or as delicatessen, and fat by-products (lards, ready-to-use broth, and gelatin). In some cases, it could also be necessary to avoid dairy products (56).
Additional tick bites must be avoided since they could further increase sIgE- $\alpha$-gal and the risk of allergic reactions to previously tolerated foods. The patient and family should be instructed on clothing type, repellent products, and the recognition and prompt removal of ticks.

Regarding treatment, the symptoms, even if delayed, must be treated as in immediate reactions. For mild reactions, oral antihistamine and steroids could be used. For severe reactions and anaphylaxis, auto-injectable adrenaline must be prescribed. An oral desensitization case report (37) on a 10-year-old boy, with two previous anaphylaxis, has also been published. Oral provocation test was performed, with a reaction after ingestion of $4 \mathrm{~g}$ of cooked beef. A 24-day desensitization protocol has allowed to reach $120 \mathrm{~g}$ of cooked beef, to be ingested daily to maintain acquired tolerance.

\section{PROGNOSIS}

Nowadays, there are no prospective studies on AGS natural history. sIgE- $\alpha$-gal levels often decline spontaneously in those who avoid tick bites (14). This decline has been demonstrated by Kim et al. (57), who also noticed that sIgE- $\alpha$-gal increases after repeated tick bites but not always with an isolated single bite. The authors underlined that it is important to periodically evaluate sIgE- $\alpha$-gal. After 12 months, if a reduction of $\operatorname{sIgE-} \alpha-$ gal $<0.35 \mathrm{kU} / 1$ or $<2 \%$ of total IgE is detected, in the absence of accidental ingestion, a gradual reintroduction of low-fat meat could be proposed.

\section{UNMEET NEEDS}

The rarity of AGS, the diagnostic delay, and the possible underdiagnosis of this allergy suggest that more studies are needed. In particular, the following are suggested:

- Epidemiological population study (ASG prevalence in subjects with meat allergy, other food allergies, and a concurrent blood type characterization)

- Determination of allergen content in different foods and drugs

- Analysis of the molecular mechanisms of delayed timing

- Evaluation of allergic co-factors and dose-response effect

- Evaluation of the cooking process and the role of other ingredients and environmental factors

- Long-term follow-up (feasibility and usefulness of early detection of sensitization)

- Evaluation of high-risk patient screening 
- Standardization of oral provocation test and
desensitization protocols
- Standardization and data collection on sensitivity and
specificity of diagnostic tests in pediatric age.

\section{CONCLUSIONS}

AGS is a rare, atypical, and under-rated allergy, less frequent in childhood but involving those living in tick-endemic areas. Red meat ingestion usually not only causes delayed reactions $(2-6 \mathrm{~h}$ after meal) but could also lead to severe reactions. Diagnosis relies on clinical history and sIgE- $\alpha$-gal determination. It is important to evaluate for AGS every patient with a history of idiopathic urticaria or anaphylaxis and unclear allergic reactions with unusual timing or characteristics. More have to be discovered on natural history, but long-term management is based on solely elimination diet and tick bite avoidance.

\section{REFERENCES}

1. Galili U. The alpha-gal epitope and the anti-gal antibody in xenotransplantation and in cancer immunotherapy. Immunol Cell Biol. (2005) 83:674-86. doi: 10.1111/j.1440-1711.2005.01366.x

2. Apostolovic D, Krstic M, Mihailovic J, Starkhammar M, Cirkovic Velickovic T, Hamsten C, et al. Peptidomics of an in vitro digested $\alpha$-Gal carrying protein revealed IgE-reactive peptides. Sci Rep. (2017) 7:5201. doi: 10.1038/s41598-017-05355-4

3. Straesser ML. $\alpha$-Gal on Crotalidae-polyvalent fab antivenom (CroFab): investigating the relevance to immediate hypersensitivity reactions. J Allergy Clin Immunol Pract. (2021) 9:1015-7. doi: 10.1016/j.jaip.2020.10.026

4. Hawkins RB, Frischtak HL, Kron IL, Ghanta RK. Premature bioprosthetic aortic valve degeneration associated with allergy to galactose-alpha-1,3galactose. J Card Surg. (2016) 31:446-8. doi: 10.1111/jocs.12764

5. Mozzicato SM, Tripathi A, Posthumus JB, Platts-Mills TAE. Porcine or bovine valve replacement in 3 patients with IgE antibodies to the mammalian oligosaccharide galactose-alpha-1,3-galactose. J Allergy Clin Immunol Pract. (2014) 2:637-8. doi: 10.1016/j.jaip.2014.04.016

6. Wilson JM, Nguyen At, Schuyler AJ, Commins SP, Taylor AM, Platts-Mills TAE, et al. IgE to the mammalian oligosaccharide galactose- $\alpha$-1,3-galactose is associated with increased atheroma volume and plaques with unstable characteristics-brief report. Arterioscler Thromb Vasc Biol. (2018) 38:16659. doi: 10.1161/ATVBAHA.118.311222

7. Commins SP. Diagnosis \& management of alpha-gal syndrome: lessons from 2,500 patients. Expert Rev Clin Immunol. (2020) 16:667-77. doi: 10.1080/1744666X.2020.1782745

8. Stoltz LP, Cristiano LM, Dowling APG, Wilson JM, Platts-Mills TAE, Traister RS. Could chiggers be contributing to the prevalence of galactose-alpha-1,3galactose sensitization and mammalian meat allergy? J Allergy Clin Immunol Practice. (2019) 7:664-6. doi: 10.1016/j.jaip.2018.07.014

9. Steinke JW, Platts-Mills TAE, Commins SP. The alpha gal story: lessons learned from connecting the dots. J Allergy Clin Immunol. (2015) 135:58997. doi: 10.1016/j.jaci.2015.01.005

10. Van Nunen SA, O'Connor K, Fernando SL, Clarke LR, Boyle R. The association between Ixodes holocyclus tick bite reactions and red meat allergy [abstract]. Intern Med J. (2007) 37:AB132. Available online at: https://www.semanticscholar.org/paper/THE-ASSOCIATION-BETWEENIXODES-HOLOCYCLUS-TICK-BITE-Nunen-O\%E2\%80\%99Connor/ 5d1ab323a9aca9b83e0ba82f419ff21ebde3cedf\#citing-papers

11. O’Neil BH, Allen R, Spigel DR, Stinchcombe TE, Moore DT, Berlin JD, et al. High incidence of cetuximab-related infusion reactions in Tennessee and North Carolina and the association with atopic history. J Clin Oncol. (2007) 25:3644-48. doi: 10.1200/JCO.2007.11.7812

12. Qian J, Liu T, Yang L, Daus A, Crowley R, Zhou Q. Structural characterization of $\mathrm{N}$-linked oligosaccharides on monoclonal antibody

\section{AUTHOR CONTRIBUTIONS}

EN conceived the study and supervised it. FS wrote the manuscript. All the authors performed the research, selection of the sources, contributed to the article, and approved the submitted version.

\section{FUNDING}

The publication fee was financed by the Italian Society of Pediatric Allergy and Immunology. However, no significant funding source could have influenced the outcomes of this work.

\section{ACKNOWLEDGMENTS}

The authors want to thank the Italian Society of Pediatric Allergy and Immunology for its support in relation to this work.

cetuximab by the combination of orthogonal matrix assisted laser desorption/ionization hybrid quadrupole-quadrupole time-of-flight tandem mass spectrometry and sequential enzymatic digestion. Anal Biochem. (2007) 364:8-18. doi: 10.1016/j.ab.2007.01.023

13. Chung $\mathrm{CH}$, Beloo Mirakhur B, Chan E, Le QT, Berlin J, Morse M, et al. Cetuximab-induced anaphylaxis and IgE specific for galactose- $\alpha-1,3-$ galactose. N Engl J Med. (2008) 358:1109-17. doi: 10.1056/NEJMoa074943

14. Commins SP, Satinover SM, Hosen J, Mozena J, Borish L, Lewis BD, et al. Delayed anaphylaxis, angioedema, or urticaria after consumption of red meat in patients with IgE antibodies specific for galactose $\alpha$ - 1,3-galactose. J Allergy Clin Immunol. (2009) 123:426-33. doi: 10.1016/j.jaci.2008.10.052

15. Commins SP, James HR, Kelly LA, Pochan SL, Workman LJ, Perzanowski MS, et al. The relevance of tick bites to the production of IgE antibodies to the mammalian oligosaccharide galactose- $\alpha$-1,3-galactose. J Allergy Clin Immunol. (2011) 127:1286-93. doi: 10.1016/j.jaci.2011.02.019

16. Hamsten C, Starkhammar M, Tran TAT, Johansson M, Bengtsson U, Ahlen $\mathrm{G}$, et al. Identification of galactose-a-1,3-galactose in the gastrointestinal tract of the tick Ixodes ricinus; possible relationship with red meat allergy. Allergy. (2013) 68:549-52. doi: 10.1111/all.12128

17. Platts-Mills TAE, Commins SP, Biedermann T, van Hage M, Levin M, Beck LA, et al. On the cause and consequences of IgE to galactose-a1,3-galactose: a report from the national institute of allergy and infectious diseases workshop on understanding IgE-mediated mammalian meat allergy. J Allergy Clin Immunol. (2020) 145:1061-71. doi: 10.1016/j.jaci.2020. 01.047

18. De la Fuente J, Pacheco I, Villar M, Cabezas-Cruz A. The alpha-gal syndrome: new insights into the tick-host conflict and cooperation. Parasites Vectors. (2019) 12:154-8. doi: 10.1186/s13071-019-3413-z

19. Chandrasekhar JL, Cox KM, Loo WM, Qiao H, Tung KS, Erickson LD. Cutaneous exposure to clinically relevant lone star ticks promotes IgE production and hypersensitivity through CD4(1) T cell- and MyD88-dependent pathways in mice. J Immunol. (2019) 203:813-24. doi: 10.4049/jimmunol.1801156

20. Iweala OI, Nagler CR. The microbiome and food allergy. Annu Review Immunol. (2019) 37:377-403. doi: 10.1146/annurev-immunol-042718-041621

21. Harrison OJ, Linehan JL, Shih HY, Bouladoux N, Han SJ, Smelkinson $\mathrm{M}$, et al. Commensal-specific $\mathrm{T}$ cell plasticity promotes rapid tissue adaptation to injury. Science. (2019) 363:eeat6280. doi: 10.1126/science.aat 6280

22. Commins SP, James HR, Stevens W, Pochan SL, Land MH, King C, et al. Delayed clinical and ex vivo response to mammalian meat in patients with IgE to galactose-alpha-1,3-galactose. J Allergy Clin Immunol. (2014) 134:108-15. doi: 10.1016/j.jaci.2014.01.024

23. Hashizume H, Fujiyama T, Umayahara T, Kageyama R, Walls AF, Satoh T. Repeated Amblyomma testudinarium tick bites are associated with increased galactose-alpha-1,3-galactose carbohydrate IgE antibody levels: a 
retrospective cohort study in a single institution. J Am Acad Dermatol. (2018) 78:1135-41. doi: 10.1016/j.jaad.2017.12.028

24. Schmidle P, Reidenbach K, Kugler C, Eberlein B, Biedermann T, Darsow U. Recall urticaria - a new clinical sign in the diagnosis of alpha-gal syndrome. $J$ Allergy Clin Immunol Pract. (2019) 7:685-6. doi: 10.1016/j.jaip.2018.08.026

25. Patel C, Iweala OI. "Doc, will I ever eat steak again?": diagnosis and management of alpha-gal syndrome. Curr Opin Pediatr. (2020) 32:81624. doi: 10.1097/MOP.0000000000000955

26. Wilson JM, Platts-Mills TAE. The oligosaccharide galactose- $\alpha$-1,3-galactose and the $\alpha$-gal syndrome: insights from an epitope that is causal in immunoglobulin E-mediated immediate and delayed anaphylaxis. EMJ Allergy Immunol. (2018) 3:89-98. doi: 10.1016/j.jaci.2018.10.029

27. Fischer J, Lupberger E, Hebsaker J, Blumenstock G, Aichinger E, Yardi AS, et al. Prevalence of type I sensitization to alpha-gal in forest service employees and hunters. Allergy. (2017) 72:1540-47. doi: 10.1111/all.13156

28. Hilger C, Fisher J, Wölbing F, Biedermann T. Role and mechanism of galactose-alpha-1,3-galactose in the elicitation of delayed anaphylactic reactions to red meat. Curr Allergy Asthma Reports. (2019) 19:314. doi: 10.1007/s11882-019-0835-9

29. Kelso JM, Greenhawt MJ, Li JT, Nicklas RA, Bernstein DI, Blessing-Moore J, et al. Adverse reactions to vaccines practice parameter 2012 update. J Allergy Clin Immunol. (2012) 130:25-43. doi: 10.1016/j.jaci.2012.04.003

30. Van Nunen S. Tick-induced allergies: mammalian meat allergy, tick anaphylaxis and their significance. Asia Pac Allergy. (2015) 5:3-16. doi: 10.5415/apallergy.2015.5.1.3

31. Mabelane T, Basera W, Botha M, Thomas HF, Ramjith J, Levin ME. Predictive values of alpha-gal IgE levels and alpha-gal IgE:total IgE ratio and oral food challenge proven meat allergy in a population with a high prevalence of reported red meat allergy. Pediatr Allergy Immunol. (2018) 29:8419. doi: 10.1111/pai.12969

32. Wilson JM, Schuyler AJ, Workman L, Gupta M, James HR, Posthumus J, et al. Investigation into the alpha-gal syndrome: characteristics of 261 children and adults reporting red meat allergy. J Allergy Clin Immunol Pract. (2019) 7:2348-58. doi: 10.1016/j.jaip.2019.03.031

33. Levin M, Apostolovic D, Biedermann T, Commins SP, Iweala OI, PlattsMills TAE, et al. Galactose-alpha-1,3-galactose phenotypes: lessons from various patient populations. Ann Allergy Asthma Immunol. (2019) 122:598602. doi: 10.1016/j.anai.2019.03.021

34. Kennedy JL, Stallings AP, Platts-Mills TA, Oliveira WM, Workman L, James HR, et al. Galactose-alpha-1,3-galactose and delayed anaphylaxis, angioedema, and urticaria in children. Pediatrics. (2013) 131:e154552. doi: 10.1542/peds.2012-2585

35. Donaldson B, Le MN. The clinical presentation of $\alpha$-gal allergy among pediatric patients with food allergy in southwest Missouri. Ann Allergy Asthma Immunol. (2019) 123:524-5. doi: 10.1016/j.anai.2019.08.022

36. Khoury JK, Khoury NC, Schaefer D, Chitnis A, Hassen GW. A tick-acquired red meat allergy. Am J Emerg Med. (2018) 36:341. doi: 10.1016/j.ajem.2017.10.044

37. Yucel E, Sipahi Cimen S, Varol S, Suleyman A, Ozdemir C, Tamay ZU. Red meat desensitization in a child with delayed anaphylaxis due to alpha-Gal allergy. Pediatr Allergy Immunol. (2019) 30:771-3. doi: 10.1111/pai.13092

38. Kinoshita M, Newton S. Alpha-gal allergy in a 6-year-old male: a case report. J Nepal Med Assoc. (2019) 57:379-81. doi: 10.31729/jnma.4557

39. Keleş S, Mehmet Gündüz M. Alpha gal specific IgE positivity due to tick bites and red meat allergy: the first case report in Turkey. Turk J Pediatr. (2019) 61:615-7. doi: 10.24953/turkjped.2019.04.023

40. Martin-Lazaro J, Núñez-Orjales R, González-Guzmán LA, González MT, Boquete M, Carballada F. Galactose-alpha-1,3-galactose (alpha-gal) allergy: first pediatric case in a series of patients in Spain. Allergol Immunopathol. (2020) 48:251-8. doi: 10.1016/j.aller.2019.07.004

41. Cabezas-Cruz A, Hodžić A, Román-Carrasco P, MateosHernández L, Duscher GG, Sinha DK, et al. Environmental and molecular drivers of the $\alpha$-gal syndrome. Front Immunol. (2019) 10:1210. doi: 10.3389/fimmu.2019.01210

42. Commins SP, Kelly LA, Rönmark E, James HR, Pochan SL, Peters EJ, et al. Galactose-a-1,3-galactose-specific IgE is associated with anaphylaxis but not asthma. Am J Respir Critical Care Med. (2012) 185:72330. doi: 10.1164/rccm.201111-2017OC

43. Gonzalez-Quintela A, Laursen ASD, Vidal C, Skaaby T, Gude F, Linneberg A. IgE antibodies to alpha-gal in the general adult population: relationship with tick bites, atopy, and cat ownership. Clin Exp Allergy. (2014) 44:10618. doi: $10.1111 /$ cea.12326

44. Morisset M, Richard C, Astier C, Jacquenet S, Croizier A, Beaudouin E, et al. Anaphylaxis to pork kidney is related to $\operatorname{IgE}$ antibodies specific for galactose-alpha-1,3-galactose. Allergy. (2012) 67:699-704. doi: 10.1111/j.1398-9995.2012.02799.x

45. Rispens T, Derksen NIL, Commins SP, Platts-Mills TAE, Aalberse RC. IgE production to $\alpha$-gal is accompanied by elevated levels of specific IgG1 antibodies and low amounts of IgE to blood group B. PLoS ONE. (2013) 8:e55566. doi: 10.1371/journal.pone.0055566

46. Hamsten C, Tran TA, Starkhammar M, Brauner A, Commins SP, Platts-Mills TAE, et al. Red meat allergy in Sweden: association with tick sensitization and B-negative blood groups. J Allergy Clin Immunol. (2013) 132:14314. doi: 10.1016/j.jaci.2013.07.050

47. Brestoff JR, Tesfazghi MT, Zaydman MA, Jackups R Jr, Kim BS, Scott MG, et al. The B antigen protects against the development of red meat allergy. J Allergy Clin Immunol Pract. (2018) 6:1790-1. doi: 10.1016/j.jaip.2018.02.010

48. Pattanaik D, Lieberman P, Lieberman J, Pongdee T, Keene AT. The changing face of anaphylaxis in adults and adolescents. Ann Allergy Asthma Immunol. (2018) 121:594-7. doi: 10.1016/j.anai.2018.07.017

49. Fischer J, Hebsaker J, Caponetto P, Platts-Mills TAE, Biedermann T. Galactose-alpha-1,3-galactose sensitization is a prerequisite for pork-kidney allergy and cofactor-related mammalian meat anaphylaxis. J Allergy Clin Immunol. (2014) 134:755-9. doi: 10.1016/j.jaci.2014.05.051

50. Fiocchi A, Restani P, Riva E, Mirri GP, Santini I, Bernardo L, et al. Heat treatment modifies the allergenicity of beef and bovine serum albumin. Allergy. (1998) 53:798-802. doi: 10.1111/j.1398-9995.1998.tb03977.x

51. Mullins RJ, James H, Platts-Mills TA, Commins SP. Relationship between red meat allergy and sensitization to gelatin and galactose-alpha-1,3-galactose. $J$ Allergy Clin Immunol. (2012) 129:1334-42. doi: 10.1016/j.jaci.2012.02.038

52. Caponetto P, Fischer J, Biedermann T. Gelatin-containing sweets can elicit anaphylaxis in a patient with sensitization to galactose- $\alpha$-1,3-galactose. $J$ Allergy Clin Immunol Pract. (2013) 1:302-3. doi: 10.1016/j.jaip.2013.01.007

53. Ebo DG, Faber M, Sabato V, Leysen J, Gadisseur A, Bridts $\mathrm{CH}$, et al. Sensitization to the mammalian oligosaccharide galactose-alpha-1,3-galactose (alpha-gal): experience in a Flemish case series. Acta Clin Belg. (2013) 68:2069. doi: 10.2143/ACB.3278

54. Platts-Mills TAE, Li RC, Keshavarz B, Smith AR, Wilson JM. Diagnosis and management of patients with the $\alpha$-gal syndrome. J Allergy Clin Immunol Pract. (2020) 8:15-23. doi: 10.1016/j.jaip.2019.09.017

55. Mehlich J, Fischer J, Hilger C, Swiontek K, Morisset M, Codreanu-Morel F, et al. The basophil activation test differentiates between patients with alpha-gal syndrome and asymptomatic alpha-gal sensitization. J Allergy Clin Immunol. (2019) 143:182-9. doi: 10.1016/j.jaci.2018.06.049

56. Commins SP. Invited commentary: alpha-gal allergy: tip of the iceberg to a pivotal immune response. Curr Allergy Asthma Rep. (2016) 16:61. doi: 10.1007/s11882-016-0641-6

57. Kim MS, Straesser MD, Keshavarz B, Workman L, McGowan EC, Platts-Mills TAE, et al. IgE to galactose- $\alpha-1,3$-galactose wanes over time in patients who avoid tick bites. JACI Pract. (2020) 8:364-7. doi: 10.1016/j.jaip.2019.08.045

Conflict of Interest: The authors declare that the research was conducted in the absence of any commercial or financial relationships that could be construed as a potential conflict of interest.

Publisher's Note: All claims expressed in this article are solely those of the authors and do not necessarily represent those of their affiliated organizations, or those of the publisher, the editors and the reviewers. Any product that may be evaluated in this article, or claim that may be made by its manufacturer, is not guaranteed or endorsed by the publisher.

Copyright (C) 2021 Saretta, Giovannini, Mori, Arasi, Liotti, Pecoraro, Barni, Castagnoli, Mastrorilli, Caminiti, Marseglia and Novembre. This is an open-access article distributed under the terms of the Creative Commons Attribution License (CC $B Y)$. The use, distribution or reproduction in other forums is permitted, provided the original author(s) and the copyright owner(s) are credited and that the original publication in this journal is cited, in accordance with accepted academic practice. No use, distribution or reproduction is permitted which does not comply with these terms. 